\title{
Reassignment of the basidiomycetous yeasts Trichosporon pullulans to Guehomyces pullulans gen. nov., comb. nov. and Hyalodendron lignicola to Trichosporon lignicola comb. nov.
}

Correspondence

Jack W. Fell

jfell@rsmas.miami.edu
Jack W. Fell and Gloria Scorzetti

Rosenstiel School of Marine and Atmospheric Science, University of Miami, 4600 Rickenbacker Causeway, Key Biscayne, FL 33149, USA

\begin{abstract}
Nucleotide sequence analyses of the hymenomycetous yeasts demonstrated that Hyalodendron lignicola should be considered as a member of the genus Trichosporon within the Trichosporonales and that Trichosporon pullulans is associated closely with the Cystofilobasidiales, rather than the Trichosporonales. Accordingly, the following proposals are made: Trichosporon lignicola comb. nov. and Guehomyces gen. nov., to accommodate Guehomyces pullulans comb. nov. in the Cystofilobasidiales.
\end{abstract}

The hymenomycetous yeasts are classified in four orders (Tremellales, Trichosporonales, Filobasidiales and Cystofilobasidiales), based on phylogenetic analyses of nucleotide sequences of the internal transcribed spacer (ITS) and the D1/D2 regions of the rDNA (Scorzetti et al., 2002). Analysis of the genus Trichosporon (Guého et al., 1989, 1992), which is the major component of the Trichosporonales, demonstrated incorrect systematic placements for Trichosporon pullulans (Lindner) Diddens \& Lodder (1942) and Hyalodendron lignicola Diddens (1934). The relationship of these two species within the hymenomycetous orders Cystofilobasidiales and Trichosporonales is demonstrated (Fig. 1) by D1/D2 maximum-likelihood phylogenetic analysis (PAUP 4.0b10) with Bayesian Markov chain Monte Carlo (MCMC) analysis credibility values (MRBAYES: Huelsenbeck \& Ronquist, 2001). Bootstrap values represent 1000 replicates from a parsimony analysis (PAUP 4.0b10).

The Trichosporonales can be separated into four clusters with the informal names of Gracile, Porosum, Cutaneum and Ovoides (Middelhoven et al., 2004). Hyalodendron resides in the Porosum cluster, whereas T. pullulans is within the Cystofilobasidiales. The present communication proposes to correct the systematic positions of these two species by creation of Guehomyces gen. nov. in the Cystofilobasidiales, with the species Guehomyces pullulans comb. nov., and by transfer of H. lignicola to the genus Trichosporon.

Published online ahead of print on 16 January 2004 as DOI 10.1099/ ijs.0.03017-0.

Abbreviations: ITS, internal transcribed spacer; LSU, large-subunit; MCMC, Markov chain Monte Carlo.

\section{Systematic placement of Trichosporon pullulans (Lindner) Diddens \& Lodder 1942}

The specific epithet pullulans was originally employed by Lindner (1895) in the genus Oidium for a yeast-like fungus that was isolated from an experimental brewery. Lindau (1907) brought the species into the genus Oospora. Subsequently, Diddens \& Lodder (1942) placed the species in the genus Trichosporon. Guého et al. $(1989,1992)$ examined the rRNA D2 region and reported that T. pullulans was phylogenetically distinct from other members of the genus Trichosporon. This finding was confirmed by sequence analyses of the small-subunit rDNA (Sugita \& Nakase, 1998), the D1/D2 region of the large-subunit (LSU) rDNA (Fell et al., 1995, 2000; Sugita et al., 2001) and the ITS (Scorzetti et al., 2002). All these studies demonstrated the phylogenetic relationship of T. pullulans to members of the Cystofilobasidiales. The latter order consists of a diversity of genera, including the teleomorphs Mrakia, Cystofilobasidium and Xanthophyllomyces and the anamorphs Phaffia, Udeniomyces and several species assigned to the genus Cryptococcus (Fig. 1).

Mrakia and Cystofilobasidium are teliospore-forming genera, whereas Xanthophyllomyces reproduces sexually via cellbud conjugation. Phaffia is an anamorphic representative of Xanthophyllomyces, whereas the anamorphic genus Udeniomyces produces large, asymmetrical ballistoconidia. T. pullulans does not share these generic characteristics. In addition, its branch position (Fig. 1) suggests that T. pullulans represents a separate cluster within the Cystofilobasidiales.

A point that has been established is the absence of a close relationship of $T$. pullulans to the Trichosporonales; the 


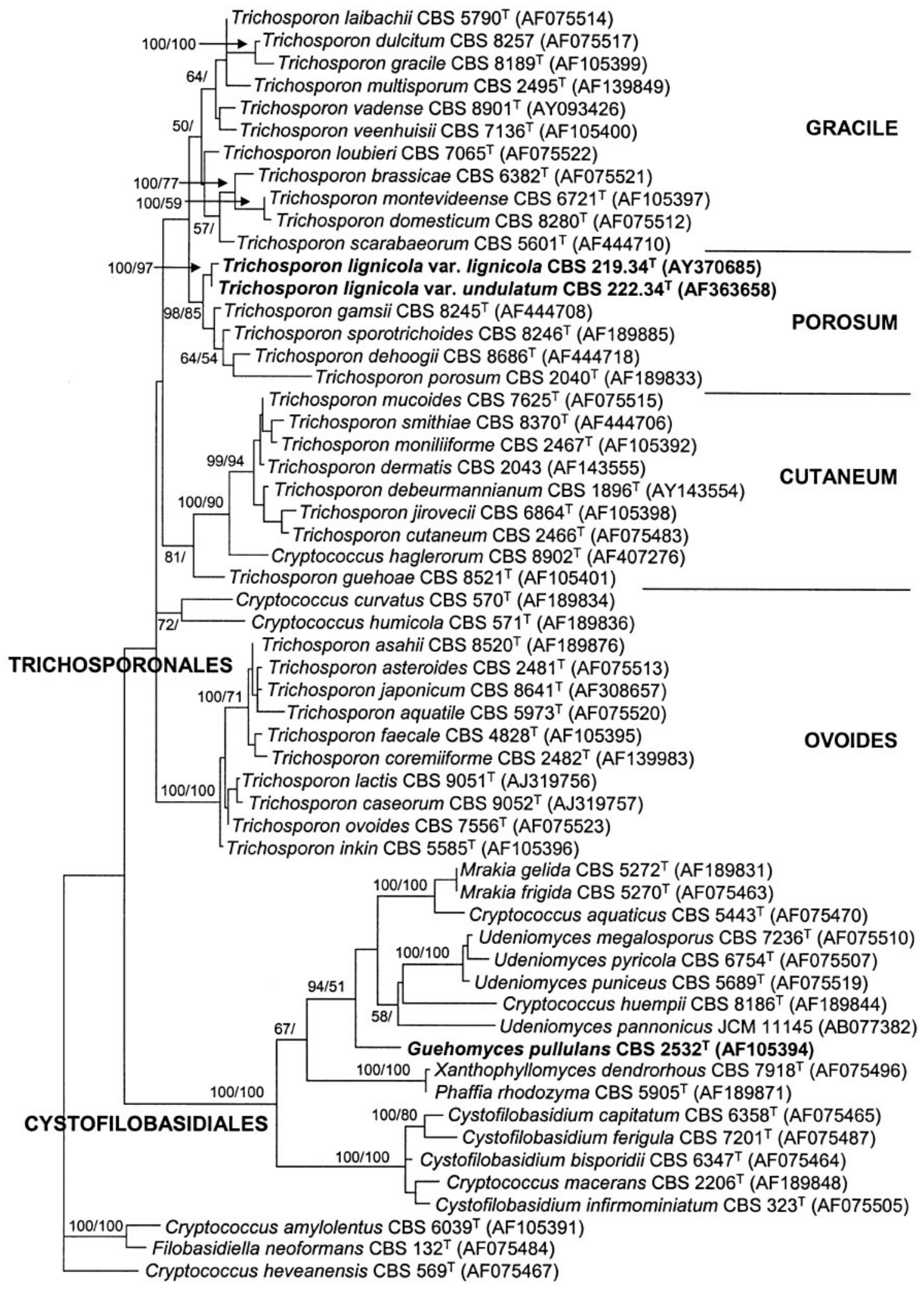

$\overline{0.01}$

Fig. 1. D1/D2 rDNA maximum-likelihood analysis (PAUP 4.0b10) of the Trichosporonales and Cystofilobasidiales. Numbers on branches represent Bayesian MCMC analysis credibility values/bootstrap values (1000 replicates from parsimony analysis). Values of $<50 \%$ (e.g. 58/) are not reported. Bar, 0.01 substitutions per site. 
semblance of similarity is based on the presence of disarticulating hyphae (arthroconidia). Arthric conidiogenesis occurs in phylogenetically diverse genera, such as Malbranchea, Coccidioides, Dipodascus and Galactomyces. Consequently, the presence of this type of conidium does not, as a sole character, link T. pullulans to the Trichosporonales. As a result, Guehomyces gen. nov. is proposed, in order to recognize this phylogenetically distinct species within the Cystofilobasidiales.

\section{Latin diagnosis of Guehomyces Fell et Scorzetti gen. nov.}

Reproductio vegetativa gemmatione enteroblastica videtur. Pseudomycelium et arthroconidia formantur. Ureum finditur, diazonium caeruleum B positivum. Reproductio sexualis nulla. Genus pertinet ad Cystofilobasidiales.

Typus: Guehomyces pullulans (Lindner) Fell et Scorzetti.

\section{Description of Guehomyces Fell \& Scorzetti gen. nov.}

Guehomyces (gu.e.ho.my'ces. N.L. masc. n. Guehomyces to recognize the outstanding taxonomic yeast research of Eveline Guého).

Budding cells that may be enteroblastic are present. Disarticulate hyphae develop arthroconidia. Tests for urease and diazonium blue B are positive. Sexual reproduction is not observed. Based on rDNA analysis, the genus is related to members of the Cystofilobasidiales. The type species is Guehomyces pullulans (Lindner) Fell \& Scorzetti comb. nov.

\section{Description of Guehomyces pullulans (Lindner) Fell \& Scorzetti comb. nov.}

Basonym: Trichosporon pullulans (Lindner) Diddens, H. A. \& Lodder, J. Die Anaskosporogenen Hefen, Zweite Hälfte, North Holland, Amsterdam 410 (1942).

Guehomyces pullulans (pul'lu.lans. N.L. part. adj. pullulans degrading pullulan).

Synonyms: Oidium pullulans Lindner (1895); Oospora pullulans (Lindner) Lindau (1907); Oosporidium fuscans Stautz (1931); Monilia pullulans (Lindner) Langeron \& Talice (1932); Trichosporon fuscans (Stautz) Buchwald (1939); Basidiotrichosporon pullulans (Lindner) KockováKratochvílová, Slavikova and Zemek (1977).

Detailed descriptions of the species were presented by Guého et al. (1992, 1998) and Barnett et al. (2000). The synonymy of Oosporidium fuscans was determined by DNA-DNA reassociation (Guého et al., 1992).

The type strain is CBS $2532^{\mathrm{T}}$.

\section{Transfer of $\boldsymbol{H}$. lignicola to Trichosporon}

H. lignicola was described by Diddens (1934) with two varieties (var. undulatum and var. simplex) from strains isolated from wood pulp in Sweden. This monotypic genus was regarded as a hyphomycetous fungus, due to the formation of dry colonies with true, disarticulating hyphae and a paucity of budding cells (de Hoog \& Smith, 1998). Typical basidiomycetous characteristics were present, i.e. positive diazonium blue $\mathrm{B}$ and urease reactions and the presence of xylose in cell walls and dolipore septa (Martínez, 1979; Guého et al., 1992; de Hoog \& Smith, 1998). The relationship of $H$. lignicola to members of the genus Trichosporon was recorded by Guého et al. (1992) with an examination of the D2 domain of the LSU rRNA. This observation was confirmed by D1/D2 and ITS rDNA analyses (Fell et al., 2000; Scorzetti et al., 2002). The relationship of $H$. lignicola to the genus Trichosporon, based on classical taxonomy and sequence evidence, was summarized by de Hoog \& Smith (1998). Consequently, it is necessary to transfer the species to the genus Trichosporon.

Classical taxonomic description of the species (de Hoog \& Smith, 1998) concluded that the three varieties (lignicola, simplex and undulatum) were synonyms. Our analysis of the D1/D2 and ITS regions of the strains lignicola (CBS 219.34 ${ }^{\mathrm{T}}$; GenBank accession numbers: ITS, AY370684; D1/D2, AY370685) and simplex (CBS 220.34; ITS, AF444481; D1/ D2, AF363657) demonstrated identical sequences for both strains. The sequence of the strain undulatum (CBS 222.34; ITS, AF444482; D1/D2, AF363658) differed from the other two strains at two nucleotide locations [transitions: transversions (Ti: Tv), 2:0] in the D1/D2 region and in the ITS region by $1 \mathrm{nt}(\mathrm{Ti}: \mathrm{Tv}, 1: 0)$. The lack of significant phenotypic and sequence differences suggests that formal acceptance of separate varieties is not warranted at this time.

\section{Description of Trichosporon lignicola (Diddens) Fell \& Scorzetti comb. nov.}

Basonym: Hyalodendron lignicola $\mathrm{H}$. Diddens. Eine neue Pilzgattung, Hyalodendron. Zentbl Bakteriol Parasitenkd Abt 2 90, 317 (1934).

Trichosporon lignicola (lig.ni'co.la. L. n. lignum wood; L. suff. - cola inhabitant, dweller; L. masc. n. lignicola wood-dweller).

Synonyms: Hyalodendron lignicola Diddens var. lignicola Diddens 1934; Hyalodendron lignicola Diddens var. simplex Diddens 1934; Hyalodendron lignicola Diddens var. undulatum Diddens 1934.

The type strain is CBS $219.34^{\mathrm{T}}$.

There are several species of Cryptococcus among the Trichosporonales: Cryptococcus haglerorum (Middelhoven et al., 2003) in the Cutaneum cluster and Cryptococcus curvatus and Cryptococcus humicola, which are represented as a separate cluster. Additionally, Takashima et al. (2001) demonstrated that Cryptococcus musae, Cryptococcus ramirezgomezianus, Cryptococcus longus and Cryptococcus pseudolongus are similar phenotypically to Cryptococcus humicola 
and represent a species complex within the Trichosporonales. The analysis by Takashima et al. (2001) was based on $18 \mathrm{~S}$ rDNA. As a result, ITS and D1/D2 sequences are not available for inclusion in our study. Those authors also reported Cryptococcus daszewskae to be related to C. curvatus. Consequently, a systematic evaluation of Cryptococcus spp. within the Trichosporonales is required.

\section{Acknowledgements}

Research support was provided by the USA National Science Foundation, Division of Environmental Biology DEB 0206521.

\section{References}

Barnett, J. A., Payne, R. W. \& Yarrow, D. (2000). Yeasts: Characteristics and Identification, 3rd edn. Cambridge: Cambridge University Press.

Buchwald, N. F. (1939). Fungi imperfecti (Deuteromycetes). Copenhagen: Kongelige Veterinaer-og Landbohojskole.

de Hoog, G. S. \& Smith, M. Th. (1998). Hyalodendron Diddens. In The Yeasts, A Taxonomic Study, pp. 773-774. Edited by C. P. Kurtzman \& J. W. Fell. Amsterdam: Elsevier.

Diddens, H. A. (1934). Eine neue Pilzgattung, Hyalodendron. Zentbl Bakteriol Parasitenkd Abt 2 90, 315-319 (in German).

Diddens, H. A. \& Lodder, J. (1942). Die Anaskosporogenen Hefen, Zweite Hälfte. Amsterdam: North Holland Publishing Company (in German).

Fell, J. W., Boekhout, T. \& Freshwater, D. W. (1995). The role of nucleotide analysis in the systematics of the yeast genera Cryptococcus and Rhodotorula. Stud Mycol 38, 129-146.

Fell, J. W., Boekhout, T., Fonseca, A., Scorzetti, G. \& StatzellTallman, A. (2000). Biodiversity and systematics of basidiomycetous yeasts as determined by large-subunit rDNA D1/D2 domain sequence analysis. Int J Syst Evol Microbiol 50, 1351-1371.

Guého, E., Kurtzman, C. P. \& Peterson, S. W. (1989). Evolutionary affinities of heterobasidiomycetous yeasts estimated from $18 \mathrm{~S}$ and 25S ribosomal RNA sequence divergence. Syst Appl Microbiol 12, 230-236.

Guého, E., Smith, M. Th., de Hoog G. S., Billon-Grand, G., Christen, R. \& Batenburg-van de Vegte, W. H. (1992). Contributions to a revision of the genus Trichosporon. Antonie van Leeuwenhoek 61, 289-316.
Guého, E., Smith, M. Th. \& de Hoog, G. S. (1998). Trichosporon Behrend. In The Yeasts, A Taxonomic Study, pp. 854-877. Edited by C. P. Kurtzman \& J. W. Fell. Amsterdam: Elsevier.

Huelsenbeck, J. P. \& Ronquist, F. (2001). MRBAYES: Bayesian inference of phylogenetic trees. Bioinformatics 17, 754-755.

Kocková-Kratochvílová, A., Sláviková, E., Zemek, J. \& Kuniak, L. (1977). The heterogeneity of the genus Trichosporon. In Proceedings of the 5th International Special Symposium on Yeasts, p. 9.

Langeron, M. \& Talice, R. V. (1932). Nouvelles méthodes d'étude et essais de classification des champignons levuriformes. Ann Parasitol Hum Comp 10, 1-80 (in French).

Lindau, G. (1907). Fungi imperfecti: Hyphomycetes. In KryptogamenFlora von Deutschland, Österreich und der Schweiz, 1 Pilze VIII Abt. Edited by L. Rabenhorst. Leipzig, Germany: Kummer.

Lindner, P. (1895). Mikroskopische Betriebskontrolle in den Gärungsgewerben mit einer Einfhrung in die Hefenreinkultur, Infektionslehre und Hefenkunde. Berlin: Parey (in German).

Martínez, A. T. (1979). Ultrastructure of Moniliella, Trichosporonoides and Hyalodendron. Stud Mycol 19, 50-57.

Middelhoven, W. J., Fonseca, A., Carreiro, S. C., Pagnocca, F. C. \& Bueno, O. C. (2003). Cryptococcus haglerorum, sp. nov., an anamorphic basidiomycetous yeast isolated from nests of the leafcutting ant Atta sexdens. Antonie van Leeuwenhoek 83, 167-174.

Middelhoven, W. J., Scorzetti, G. \& Fell, J. W. (2004). Systematics of the anamorphic basidiomycetous yeast genus Trichosporon Behrend with the description of five novel species: Trichosporon vadense, T. smithiae, T. dehoogii, T. scarabaeorum and T. gamsii. Int J Syst Evol Microbiol 54, 975-986.

Scorzetti, G., Fell, J. W., Fonseca, A. \& Statzell-Tallman, A. (2002). Systematics of basidiomycetous yeasts: a comparison of large subunit D1/D2 and internal transcribed spacer rDNA regions. FEMS Yeast Res 2, 495-517.

Stautz, W. (1931). Beitrage zur Schleimflussfrage. Phytopathol Z 3, 163-229 (in German).

Sugita, T. \& Nakase, T. (1998). Molecular phylogenetic study of the basidiomycetous anamorphic yeast genus Trichosporon and related taxa based on small subunit ribosomal DNA sequences. Mycoscience 39, 7-13.

Sugita, T., Takashima, M., Nakase, T., Ichikawa, T., Ikeda, R. \& Shinoda, T. (2001). Two new yeasts, Trichosporon debeurmannianum sp. nov. and Trichosporon dermatis sp. nov., transferred from the Cryptococcus humicola complex. Int J Syst Evol Microbiol 51, $1221-1228$.

Takashima, M., Sugita, T., Shinoda, T. \& Nakase, T. (2001). Reclassification of the Cryptococcus humicola complex. Int J Syst Evol Microbiol 51, 2199-2210. 